\title{
Experiência do Leaal/UFPE na produção e transferência de tecnologia*
}

\section{Cecília Prysthon}

\section{Susana Schmidt}

Professoras do Curso de Biblioteconomia da Universidade Federal de Pernambuco. Centro de Ciências da Saúde. Departamento de Nutrição. Leaal - Laboratório de Experimentação e Análises de Alimentos: folder. Recife, [1997?]

cmfp@npd.ufpe.br

susach@npd.ufpe.br

\section{Resumo}

O Laboratório de Experimentação e Análise de Alimentos (Leaal) do Departamento de Nutrição do Centro de Ciências da Saúde da Universidade Federal de Pernambuco cria/desenvolve e transfere tecnologia para o setor produtivo. Na sociedade industrial, transferência de tecnologia implica comunicação de informação tecnológica relevante para a produção de bens e serviços. Além das barreiras que interferem na comunicação final da informação, os mecanismos de visibilidade muitas vezes não são adequados ao acesso nos sistemas tradicionais e/ou automatizados de comunicação da informação tecnológica. Este trabalho trata de informação tecnológica, sua criação, desenvolvimento de bens e serviços até sua transferência e incorporação pela sociedade. Apresenta ações e mudanças necessárias ao laboratório para tornar visíveis e mais adequados os mecanismos de transferência tecnológica no âmbito da universidade e comunidade externa.

\section{Palavras chave}

Informação tecnológica; Transferência de informação; Transferência tecnológica.

\section{Leaa/Ufpe experience in technology production and transfer}

\begin{abstract}
The Laboratory for Experimentation and Analysis of Food (Laboratório de Experimentação e Análise de Alimentos - LEAAL) of the Nutrition Department of The Health Sciences Centre in the Federal University of Pernambuco creates and develops technology for the productive sector. In the industrial societies, technology transfer implies the communication of relevant technological information to the production of goods and services. Besides the barriers that interfere in the final communication of information, its mechanisms of visibility are often inadequate in both traditional and computerized systems of communication of technological information. This work deals with technological information, its creation, development of goods and services, including its transfer to and assimilation by society. Actions and changes needed for the laboratory to make the mechanisms of technological transfer more visible and appropriate, as far as university and external community is concerned, are presented.
\end{abstract}

\section{Keywords}

Technological information; Information transfer; Technological transfer.

\section{INTRODUÇÃO}

O desenvolvimento de uma sociedade sustenta-se na atividade econômica, que, como um todo, deve suprir as necessidades biológicas dos cidadãos, de tal modo que todos alcancem níveis aceitáveis quanto à alimentação, saúde, transporte, moradia e lazer.

Observa-se que a produção de bens e serviços dos institutos de pesquisas e universidades, ainda insuficiente e incipiente, não atinge o setor produtivo privado ou estatal de modo eficaz, isto é, as tecnologias não são transferidas adequadamente. Seria como se existissem dois sistemas incomunicáveis e independentes: a pesquisa tecnológica e o sistema produtivo nacional.

O desenvolvimento e a transferência de uma tecnologia devem obedecer a uma sistemática decisória em etapas progressivas, objetivando minimizar custos e riscos envolvidos. Portanto, a existência de demanda para o bem ou serviço correspondente é condição necessária para uma tecnologia ser transferida, e é através do conhecimento da demanda que se pode identificar a natureza ou tipo de inovação tecnológica orientando os trabalhos de pesquisa e desenvolvimento.

Logo, é de fundamental importância que as instituições de pesquisa e as universidades disponham de mecanismos de articulação e convivência com esta demanda tecnológica, a fim de efetivamente contribuir para o desenvolvimento econômico e social por meio da geração e transferência de tecnologias. Segundo Pinheiro (1991), "a informação, no seu contexto mais amplo, entendida como um dos produtos finais destas instituições e universidades, seja em forma de publicações, de pareceres técnicos e até em nível de consultoria propriamente dita, constitui-se no principal elo entre as instituições de apoio às indústrias e o parque produtivo".

\footnotetext{
* Extraído do trabalho de conclusão do II Curso de Especialização em Informação Tecnológica - DCI / UFPE, 1998, de autoria de Cecília Prysthon, sob a orientação da professora Maria Auxiliadora de Carvalho.
} 
Falta, em geral, conhecimento recíproco no que diz respeito a interesses, necessidades e capacitações. Seria então de fundamental importância a criação de uma programação destinada a profissionais de ambos os lados - universidade e empresa - identificando áreas de interesse comum e áreas próximas ou correlatas.

Parece ser um ponto importante o fato de o técnico da empresa encarar o pesquisador como alguém envolvido em assuntos de alta transcendência teórica, sem qualquer ligação com a realidade da empresa. De sua parte, o pesquisador imagina que os problemas da empresa não apresentam atrativo por serem muito específicos, resolvidos de maneira primária e visarem a fins lucrativos. A questão parece ser mais visível quando referida ao contexto de uma universidade nordestina ainda tentando fortalecer/criar parcerias com um parque industrial em crescimento e a ser cativado.

O assunto transferência de informação tecnológica é objeto deste estudo, em que o problema de visibilidade do domínio tecnológico alcançado pelo Departamento de Nutrição, por intermédio de seu Laboratório de Experimentação e Análise de Alimentos (Leaal), será discutido a partir de análise da produção técnicocientífica daquele laboratório, como também de referências teóricas sobre o assunto.

Da literatura da área de informação, faz-se uma breve introdução ao assunto a partir do ponto de vista de artigos de revistas especializadas, bem como de outros tipos de fontes que embasam a metodologia utilizada e ajudam a responder à relação entre a criação de tecnologia e transferência da informação gerada.

\section{O CONTEXTO DA INTERAÇÃO ENTRE UNIVERSIDADE E SOCIEDADE NO ÂMBITO DA TECNOLOGIA}

Discutir as formas de interação entre universidade/ institutos de pesquisa e setor produtivo exige que se reflita primeiramente sobre a aceitação do papel de cada entidade. Contudo, entre os parceiros, parece haver muito preconceito e/ou discriminação generalizados. Já é hora, portanto, de buscar e/ou criar estratégias que viabilizem um entendimento de alto nível capaz de selar a cooperação entre pesquisadores e empresários, pois interação é um processo através do qual duas instituições procuram completar suas funções. É possível e viável haver um esforço conjugado da empresa e da universidade de forma que ambas possam melhor cumprir suas funções sociais, econômicas, culturais e políticas.
De acordo com Oliveira, Otero \& Schmidt (1994), "A universidade - reagindo a críticas de que o academicismo tem favorecido o crescimento de pesquisas desligadas da realidade do cotidiano, desconhecendo assim os problemas ligados à produção e ao mercado - preocupase não só em capacitar mão-de-obra especializada, mas também em participar da qualificação de pesquisadores que efetivamente possam gerar e garantir meios”.

A compreensão da necessidade de integrar ações desenvolvidas no âmbito das universidades e das empresas, como meio de fortalecimento das capacidades para busca de soluções conjuntas, favoreceu o surgimento de diversos programas de cooperação que objetivam promover, estimular, propiciar e otimizar a estreita relação entre universidades e o setor empresarial, difundindo, valorizando, transferindo e maximizando o uso da informação tecnológica, sobretudo, como afirma Zagottis (1995), "quando o sistema produtivo precisa absorver uma tecnologia nova para ele, ou quando o setor científico desenvolve conhecimentos novos que podem ter aplicações práticas”.

Estas ações interativas privilegiam o desenvolvimento tecnológico na busca de soluções novas e abrangentes e de interesse nacional, mediante captação de recursos diretamente com os setores envolvidos.

Por isso, as ações universidade-empresa, embora reconhecidas, são questionáveis, pois o conhecimento tecnológico existente nas instituições de pesquisa está ou não disponibilizado, normalmente, por falta de uma organização que o torne de fácil uso e que seja incorporado pelo sistema produtivo, principalmente por parte da micro e pequena empresa, como meio de fortalecimento das capacidades para busca de soluções em benefício da sociedade.

O conhecimento é produto da acumulação, sistematização e uso de uma informação precedente. A informação é a base para tomada de decisão e instrumento essencial para o êxito de qualquer empresa. De acordo com Pinto (1992), "informação é o quarto fator de produção junto com a terra e se trata de recurso econômico com efeito multiplicador, não se gasta com o uso, pode duplicar-se e transmitir-se a qualquer parte; é um recurso ideal para ser compartilhado".

No desenvolvimento da sociedade, a informação ocupa posição de destaque cada vez maior, considerando-se a explosão documental derivada dos avanços científicos e tecnológicos, a elevação dos níveis educacionais da 
população, as necessidades de informação para sobreviver e progredir em um mundo cada vez mais complexo, competitivo e interdependente.

Vale salientar que a informação tem sido fator determinante de domínio tecnológico em instituições científicas e tecnológicas. No final do século XIX, nasce a figura do laboratório empresarial de pesquisas tecnológicas e desenvolvimento experimental nos Estados Unidos, que, de acordo com Zagottis (1995), "disseminaram-se pelo mundo desenvolvido, tendo hoje três funções básicas", quais sejam, criar inovações, absorvê-las e transferi-las.

O domínio tecnológico é conseguido por meio do insumo básico - a informação -, que possui natureza técnica, científica e econômica, mercadológica e gerencial. Tem como canais de distribuição meios formais e informais e está relacionado com a competência na aplicação de tecnologia, criando a condição de autonomia e domínio tecnológico, este embasado em seus fatores de factibilidade, confiabilidade e competitividade.

Com o acirramento da competitividade industrial e a diminuição gradativa do ciclo de vida dos produtos, o setor produtivo, para se manter dentro dos três fatores básicos do domínio tecnológico, necessita de investimentos cada vez maiores em pesquisa tecnológica para alcançar padrões internacionais de qualidade.

Necessário se faz mencionar, dentro da visão de domínio tecnológico, a gestão da inovação, como salienta Marcovitch (1993), que "nos tempos atuais os produtos são mais valorizados pelos conhecimentos neles incorporados, do que pelas matérias-primas ou mão-deobra embutidas". Ocorre então a industrialização da ciência, tornando cada vez mais complexo o processo de criação/desenvolvimento de tecnologia, o que, segundo o mesmo autor, "requer o planejamento de ações não só no campo da pesquisa científica e tecnológica, como fonte de novos conhecimentos e tecnologias, mas também ações para compreender e gerenciar os mecanismos que afetam a difusão destes conhecimentos, a transferência das tecnologias, sua incorporação e utilização no sistema produtivo e na sociedade".

De acordo com Barreto (1992), a área tecnológica tem merecido grande atenção na discussão sobre a importância da tecnologia no desenvolvimento como fator determinante da posição dos diferentes países, em termos de produtividade, padrão de vida e participação na repartição do produto em nível nacional. Para o mesmo autor, definir tecnologia nos sentidos amplo e/ou restrito é tarefa árdua, pois a quantidade de escritos sobre o assunto é muito grande e é freqüente a utilização de conceitos inadequados e imprecisos.

Dentro desse contexto de idéias, cabe então destacar o conceito de informação tecnológica, assim definido pela FID: todo conhecimento de natureza técnica, econômica, mercadológica, gerencial, social etc. que, por sua aplicação, favoreça o progresso na forma de aperfeiçoamento e inovação (Aguiar, 1991).

Por sua vez, a maioria dos estudos e propostas para a área tecnológica destaca a informação tecnológica ou informação para a indústria como aquela "informação de natureza econômica, social, política, legal e tecnológica que está relacionada a todas as etapas do desenvolvimento do setor produtivo, indo desde o projeto de implantação de uma indústria, até a comercialização do produto e o feedback do seu consumidor", conforme Pinto (1992).

Considerando-se que "a ciência e a tecnologia têm como essência o processo de transformação de informações", Furtado (1981) atesta que toda a produção de tecnologia envolve atividades de pesquisa e desenvolvimento compreendendo o uso sistemático de conhecimentos científicos ou não. Assim a informação constitui-se "conhecimento acumulado, fator de produção, operadora de ações e instrumento de reprodução ou transformação das relações sociais", como proposto por Oliveira (1992).

Como matéria-prima da ciência, da tecnologia e da indústria de ponta, a informação em seus aspectos científico e tecnológico visa a contribuir para a acumulação de bens culturais, enquanto no aspecto tecnológico utiliza a informação para gerar produtos e processos.

A criação/desenvolvimento de tecnologia depende basicamente da informação tecnológica absorvida pelo setor produtivo e a transferência de tecnologia do exterior. Vale salientar as enormes dificuldades encontradas no país para se criar/desenvolver e, principalmente, transferir tecnologias.

A transferência de tecnologia é sobretudo a absorção de um modus operandi por meio do embasamento informacional que criará algo inovador em termos de processos tecnológicos. Inserido no sistema de trocas econômicas e simbólicas da sociedade industrial, o processo de transferência de tecnologia inclui a comunicação da informação tecnológica, pois tecnologia representa conhecimento científico, técnico, econômico 
e cultural que torna possível a concepção, planejamento, desenvolvimento, produção e distribuição de bens e serviços, conforme Neelameghan apud Freire (1991).

A verdadeira transferência de tecnologia ocorre quando o receptor absorve o conjunto de conhecimentos que lhe permite inovar, isto é, a transferência se completa quando o comprador (cliente/usuário) domina o conhecimento envolvido, transpõe barreiras e fica em condições de criar novas tecnologias, gerando mais conhecimentos, transformando, inovando, criando.

\section{METODOLOGIA}

O Departamento de Nutrição, do Centro de Ciências da Saúde, foi criado em 16 de março de 1956, por proposta do professor Nelson Chaves e dirigida ao diretor da Faculdade de Medicina da Universidade Federal de Pernambuco (UFPE), como Instituto de Nutrição.

Em 1975, com a reformulação da estrutura vigente na UFPE, onde centros e departamentos passaram a coordenadores das atividades de ensino, pesquisa e extensão, o Departamento de Nutrição reestruturou-se e passou a funcionar plenamente tendo como objetivo geral "gerar, transmitir e aplicar conhecimentos na área de nutrição, com ênfase em problemas regionais e nacionais." No cumprimento desse objetivo, o Departamento está estruturado em seis laboratórios e dois cursos, além da Secretaria Geral e a Biblioteca Especializada.

Os laboratórios são os seguintes: Laboratório de Fisiologia da Nutrição (Lafisn); Laboratório de Bioquímica da Nutrição (LBQN); Laboratório de Nutrição Clínica (LNC); Laboratório de Nutrição Experimental (LNE); Laboratório de Nutrição em Saúde Pública (LNSP); Laboratório de Experimentação e Análise de Alimentos (Leaal).

Na leitura das atividades de ensino, linhas de pesquisa, convênios e assessorias desenvolvidas pelos seis laboratórios, foi escolhido o Leaal como aquele que mais se aproximou da linha de investigação deste trabalho, como prestador de serviços que resultam em criação, desenvolvimento e transferência da informação gerada.

O Leaal, inicialmente denominado Departamento de Experimentação Dietética, possui as seguintes linhas de pesquisa: a) pesquisas analíticas e tecnológicas de matérias-primas convencionais ou não encontradas na região: composição, interação entre constituintes, fisiologia pós-colheita, preservação, desenvolvimento de novas tecnologias e produção de biomassa; b) avaliação da eficiência e eficácia do processamento de alimentos: controle de qualidade e estabelecimento de parâmetros dos alimentos e serviços de distribuição de alimentos. O laboratório está constituído dos setores de planta piloto para processamento e alimentos, setor de bromatologia, setor de microbiologia de alimentos, setor de dietética e análise sensorial, setor de microscopia e setor de alimentação institucional.

Sua atuação é constante em assessoria comunitária, por meio de diversos órgãos governamentais, empresas privadas, pessoas físicas e programa interativo universidade/empresas, pelos quais são prestados serviços nas áreas de controle de qualidade de alimentos, desenvolvimento de produtos, organização de cursos, treinamento e reciclagem de profissionais ligados às indústrias de alimentos ou às instituições acadêmicas.

Os conveniados Fundação de Alimentação Estadual (FAE) e Serviço Brasileiro de Apoio às Micro e Pequenas Empresas (Sebrae) atestam seus serviços nas áreas de controle de qualidade de alimentos e desenvolvimento de produtos, e desta forma o Leaal vem se firmando como um órgão de apoio às indústrias de alimentos e serviços de alimentação de Pernambuco e demais estados do Nordeste brasileiro.

A questão central para a tarefa de investigação é a seguinte: quais as condições existentes no Leaal quando da produção de tecnologia e sua transferência para a sociedade?

Historicamente, o Departamento de Nutrição vem contribuindo na questão alimentar melhorando a situação nutricional do Nordeste sem perder de vista o contexto atual nos campos político-econômico-social. Nota-se, com isso, a tentativa de alcançar um domínio tecnológico apropriado para a região, com aproveitamento de matériasprimas locais, em condição de competir no mercado. Em contrapartida, este tipo de direcionamento procura minimizar a dependência tecnológica imposta, muitas vezes, por culturas exógenas.

E é neste contexto que se observam os esforços do Departamento de Nutrição e seus laboratórios em estimular a produção de tecnologia, no âmbito nutricional, atendendo a uma demanda considerável. Vale ressaltar a localização deste departamento inserido em uma universidade nordestina, em um espaço dotado de frágil atividade produtiva, geograficamente distante em relação aos centros industriais de maior porte, mas que tem se revelado um pólo onde vem ocorrendo a produção e transferência de tecnologia. 
A produção de tecnologia traz em seu bojo a criação em si, o componente inovação, o insumo da informação e os incentivos financeiros aliados à geração de bens e serviços capazes de suprir as necessidades econômicas do homem.

\section{PROCEDIMENTOS DA INVESTIGAÇÃO SOBRE A PRODUÇÃO, INFORMAÇÃ̃O E TRANSFERÊNCIA DE TECNOLOGIA}

Como se dá a produção, informação e transferência de tecnologia no Leaal? O tema escolhido tem como justificativa a convicção da importância da tríade da questão acima em um instituto de pesquisa, alinhando-se o Departamento de Nutrição como um gerador de bens e serviços na área de análise, produção e melhoria de alimentos.

Para o entendimento da integração das ações desenvolvidas no âmbito das universidades e empresas, procedeu-se à análise da literatura e de relatórios (de pesquisas, de serviços, de produtos) que pudessem comprovar a aplicabilidade da ação conjunta entre o Laboratório de Experimentação e Análise de Alimentos (Leaal) e a comunidade empresarial.

$\mathrm{Na}$ revisão da literatura, procurou-se identificar focos contextuais que interferem no gerenciamento dos mecanismos de difusão e transferência de tecnologia, sua incorporação e utilização no sistema produtivo da sociedade. Muitas vezes as tecnologias criadas ou desenvolvidas em institutos de pesquisa derivam de suas teses e/ou linhas de pesquisa. É inegável que a criatividade em questão no estudo é precedida de extenso e intenso esforço, sendo seguida de longos períodos de trabalho, de experimentação e reformulação.

Com base então na literatura, foi utilizado o método de observação dos procedimentos empregados na criação de bens e serviços destinados ao consumo da comunidade interna da UFPE, como também aqueles destinados à clientela externa, procurando detectar como está sendo conduzido o processo de transferência de tecnologia e os pontos de concordância com o que a literatura preconiza.

Após estas ações, foram efetuadas visitas ao referido laboratório em busca de relatórios ou outros documentos similares, além de consultas à Internet que revelassem a divulgação da produção e transferência de tecnologia desse laboratório.
Neste encaminhamento, pretende-se então demonstrar a visibilidade do trabalho executado no Leaal e sugerir alternativas para que esta visibilidade ou a divulgação das informações possam ser aprimoradas.

\section{O LABORATÓRIO DE EXPERIMENTAÇÃO E ANÁLISE DE ALIMENTOS - INTERAÇÃO E DIVULGAÇÃO DE SEUS SERVIÇOS E PRODUTOS}

As transformações ambientais (políticas, econômicas, sociais e tecnológicas) associadas ao crescimento da competição de mercado e à demanda de qualidade por parte dos usuários/clientes levam as organizações/ instituições a valorizar a informação, o conhecimento e a inteligência como recursos estratégicos dos mais valiosos.

Nesta perspectiva, a produção do conhecimento é entendida como uma verdadeira indústria : a indústria da informação e a indústria da transferência da informação. Esta última corresponde a todos os segmentos ou atividades relacionados com a produção do conhecimento - disseminação, acesso, uso e assimilação da informação voltada para setores específicos.

A transferência de tecnologia em sua forma mais freqüente ocorre mediante contratos firmados entre empresas, quando uma parte (o laboratório) se compromete a transferir para a outra ( o setor produtivo) um certo conjunto de conhecimentos ou a prestar-lhe um serviço técnico (consultoria, assistência técnica), nos prazos e nas condições estabelecidas, mediante remuneração previamente acertada.

O Laboratório de Experimentação e Análise de Alimentos (Leaal) sem dúvida se insere como um pólo de concorrência no mercado de alimentos e com possibilidades de lucro. Ele representa um avanço na interação universidade-empresa em benefício da sociedade, contribuindo também para que a universidade desenvolva o processo de autonomia marcado por decisão, determinação e auto-sustentação.

Pode-se deduzir que os produtos oferecidos pelo Leaal à comunidade local se caracterizam por possuir credibilidade e competência conforme atestam convênios renovados com o Sebrae e a FAE. Isto vale também para os serviços de consultoria para implantação e ampliação de indústrias e restaurantes industriais; controle de qualidade de água, bebidas não alcoólicas e alimentos; biotecnologia de alimentos e bebidas; higiene industrial e desenvolvimento de alimentos funcionais. Como exemplos de assessorias bem-sucedidas pode-se mencionar trabalhos para as 
seguintes empresas: Sucos Naturais, Gelisa, Água Serra Branca, São Marcos, Chesf, Lafepe e outras. As atividades desenvolvidas pelo Laboratório são de responsabilidade de pesquisadores/professores, técnicos e estudantes de nutrição.

Quanto à incorporação de conhecimentos empregados na comercialização de bens e serviços, as dissertações apresentadas nos últimos quatro anos (1993-1996) produzidas pelo Curso de Mestrado em Nutrição indicam que os bens advindos do Leaal têm sido objeto de investigação, com fortes possibilidades de serem enriquecidas com as contribuições próprias destes estudos.

Quanto à divulgação desta interação existente entre a universidade-empresa, concretizada pelo Leaal, foram encontrados mecanismos como organização de eventos locais, ou seja, a Jornada Nordestina de Nutrição em sua $14^{\mathrm{a}}$ versão, com resultados positivos de visibilidade da produção desenvolvida no departamento como um todo (contemplando seus alunos a partir de estágios curriculares); participação em eventos regionais, nacionais e internacionais; publicações de trabalhos e artigos em anais, periódicos, boletins e relatórios e expressiva quantidade de citações em periódicos nacionais e estrangeiros.

A tecnologia é, portanto, transferida por pessoas ou documentos que contêm a informação. Há alta concentração de criação tecnológica no Departamento de Nutrição e nos seus diversos laboratórios, notadamente no Leaal. Isto pode ser observado em uma análise quantitativa, na transferência de tecnologia para o setor produtivo (convênios) e da informação impressa para a biblioteca. No segundo caso, existe um levantamento da bibliografia institucional dos anos de 1993-1995, sob a responsabilidade da Biblioteca Setorial do Departamento de Nutrição (Costa, 1995).

Confirma-se ainda a existência de canais formais e informais de transferência da informação por meio dos trabalhos apresentados em eventos (locais, nacionais e internacionais). Neles os pesquisadores geram, transmitem e aplicam conhecimentos na área de experimentação e análise de alimentos, cumprindo seus objetivos de forma que estes sejam agregados, valendo mais do que as matérias-primas e a mão-de-obra utilizadas (Marcovitch, 1993). Entre cerca de vinte trabalhos de pesquisa com resultados práticos - produtos e serviços - e posteriormente editados entre 1993-1996, observou-se a criação/desenvolvimento de bens e serviços, utilizando matérias-primas da região e aplicação de tecnologia própria.
A comprovação de que a pouca visibilidade nos processos de transferência da informação é responsável pelo pouco conhecimento da produção de bens e serviços no Leaal e, conseqüentemente, por uma demanda reprimida desta produção gera questionamentos, não somente em relação à nova postura do departamento, mas também no tocante à gerência de todo o processo de criação/desenvolvimento e transferência de tecnologia.

A análise dos textos permitiu verificar aspectos importantes e conflitantes com a idéia de criação/ desenvolvimento e transferência de informação tecnológica. De posse de alguns resultados, é possível indicar prováveis correlações e explicações. Ressalvadas as limitações desse estudo, constata-se a importância de:

a) mudanças (cognitivas e de ação) no sentido de criar meios que permitam cliente/usuário buscar a informação desejada nas fontes adequadas, ligando o laboratório à rede e a sistemas automatizados, locais, nacionais e internacionais;

b) acompanhamento das políticas em $\mathrm{C} \& \mathrm{~T}$ que subsidiarão os processos de criação de novos serviços e produtos;

c) definição clara das necessidades dos usuários/clientes do laboratório em face da enorme gama de tipos de informação e a variedade de demandas passíveis de serem disponibilizadas nas bibliotecas, centros e serviços de informação;

d) convicção de que a informação tecnológica possibilitará o desenvolvimento econômico e social, mediante geração e transferência de tecnologia;

e) articulação entre universidade e setor produtivo nos mecanismos de oferta e demanda tecnológica;

f) direcionamento de tecnologias mais despojadas para resolver problemas de comunidades carentes com desenvolvimento de alimentos funcionais;

g) desenvolvimento, e não compra, de pacotes tecnológicos alienígenas, que, além de onerar os cofres das instituições, inviabilizam a plena capacidade inovadora dos pesquisadores.

Caberia avaliar o fluxo de informação, sua transferência e canais de comunicação para adoção de medidas que melhorem a visibilidade dos processos no Leaal, sejam de ordem tecnológica como também os de ordem gerencial para que "o conjunto de todos os conhecimentos - 
científicos, empíricos ou intuitivos - empregados na comercialização de bens e serviços", como define Pirró \& Longo apud Barreto (1992), seja o elemento fundamental da produção e transferência de tecnologia desenvolvidas e absorvidas pelo setor produtivo.

\section{CONCLUSÃO}

O Departamento de Nutrição do Centro de Ciências da Saúde da Universidade Federal de Pernambuco assume novos papéis e nova postura, não se limitando apenas à formação de recursos humanos e à geração de conhecimentos científicos. Ampliando sua ação de gerador, transmissor e aplicador de conhecimentos na área de nutrição, coloca-se como um órgão de apoio à comunidade acadêmica e à sociedade em geral, assessorando e treinando empreendedores na consecução do objetivo maior de intensificação do processo de industrialização, visando a tornar menos agudos os problemas de dependência externa do país.

De fato, acontece o processo de produção de bens e serviços no Leaal, conforme subsídios dos diversos trabalhos selecionados. $\mathrm{O}$ acesso às pesquisas ali desenvolvidas é passível de melhoria, diante daquela demanda por informação técnica, principalmente por pequenas e médias empresas do ramo alimentício. A otimização dos sistemas de comunicação já existentes é campo para inúmeras inovações à luz das mais modernas tecnologias. Uma ampla base de informações científicas e tecnológicas, que é considerada uma vantagem, torna-se uma necessidade vital. É também essencial a participação em redes e sistemas ligados à biblioteca especializada do Departamento de Nutrição. Como conseqüência, será observado um aumento significativo no número de parcerias, expansão dos meios de intercâmbio de informações e de cooperação científica e tecnológica.

Formar parcerias, assessorar e treinar empreendedores, no duplo processo de produção de bens e serviços e de transferência de tecnologia, constitui-se uma nova dimensão que vem proporcionando grandes avanços no primeiro mundo, e no contexto do Brasil é praticamente inédito em nossa literatura profissional, mas validada para questões mais amplas no âmbito das políticas e programas nacionais de informação científica e tecnológica.

Apenas o que pode ser antevisto neste momento é a necessidade de se buscar a interação universidade empresa, o cumprimento das políticas de $\mathrm{C} \& \mathrm{~T}$, a visibilidade dos processos de criação e de transferência de tecnologia, a interdisciplinaridade (ciência da informação, informática, nutrição), que, por sua vez, possam conduzir a um maior entendimento dos complexos problemas de autonomia tecnológica, fator de desenvolvimento sóciohistórico-econômico-cultural de um país.

Relato de Experiências aceito para publicação em 21-12-2001.

\section{REFERÊNCIAS BIBLIOGRÁFICAS}

AGUIAR, A. C. de. Informação e atividades de desenvolvimento científico, tecnológico e industrial: tipologia proposta com base em análise funcional. Ciência da Informação, Brasília, v. 20, n. 1, p. 7-15, 1991.

BARRETO, A. A. Informação e transferência de tecnologia: mecanismos de absorção de novas tecnologias. Brasília : IBICT, 1992. 64 p.

COSTA, M. C. M. de A. (Org.). Quarenta anos de nutrição no Nordeste: uma retrospectiva. Recife : Ed. Universitária da UFPE, 1995. 2 v.

FREIRE, I. M. Barreiras na comunicação da informação tecnológica. Ciência da Informação, Brasília, v. 20, n. 1, p. 51-54, jan./jun. 1991.

FURTADO, J. S. Conceitos e tipologias em ciência e tecnologia e sua influência na publicação de informações. Ciência da Informação, Brasília, v. 10, n. 1, p. 13-18, 1981.

MARCOVITCH, J. Gestión de la innovación y desarrollo tecnológico. In: PLONSKI, G. A. (Ed.). Cooperación empresa-universidade en Iberoamerica. São Paulo : CYTED, 1993. 288 p.

OLIVEIRA, M. C. G. O papel da informação no processo de transferência de tecnologia industrial. Informação \& Sociedade: Estudos, João Pessoa, v. 2, n. 1, p. 25-37, 1992.

OliveirA, M. C. G.; OTERO, M. M. D. F. ; SCHMIDT, S. Serviços de informação tecnológica: integração universidade e sociedade. In: SEMINÁRIO NACIONAL DE BIBLIOTECAS UNIVERSITÁRIAS 8, 1994, Campinas. Anais... Campinas : UNICAMP, 1994. p. 165-173.

PINHEIRO, M. G. Informação para a indústria. Ciência da Informação, Brasília, v. 20, n. 1, p. 16-19, jan./jun. 1991.

PINTO, V. B. Informação para a indústria : a experiência da NRI-CE na prestação de serviço de respostas técnicas a micro, pequenas e médias indústrias. 1992. 189 f. Dissertação (Mestrado) - Departamento de Biblioteconomia - Universidade Federal de Minas Gerais, Belo Horizonte, 1992.

ZAGOTTIS, D. I. de. A interação entre a universidade e o sistema produtivo. Revista de Ensino de Engenharia, Brasília, n. 15, dez. 1995. 